\title{
SLEEP DISORDERS IN LATE-LIFE DEPRESSION
}

\author{
Angkawidjaja KMA*, Soetjipto** \\ * Dokter Umum, Peserta PPDS I Prodi Psikiatri Departemen/SMF Ilmu Kedokteran Jiwa FK UNAIR/RSUD dr. Soetomo Surabaya \\ **Psikiater Konsultan, Staf Pengajar Departemen/SMF Ilmu Kedokteran Jiwa FK UNAIR/RSUD dr. Soetomo Surabaya
}

\begin{abstract}
Depression is an important mental health problem in developed societies, and as many as 50\%-90\% of patients with depression complain of sleep disorders. In the elderly, sleep disorders comorbid depressive disorders are getting worse. Late-life Depression (LLD) is often not detected because the symptoms are less specific than younger age. It even provides an independent risk factor impact on suicide ideas and behaviour. Causative risk factors of sleep disorders in Late-life Depression are biological and non-biological factors that form the basic of pharmacological and nonpharmacological management.
\end{abstract}

Keywords: depression, late-life depression, sleep disorders

Corresponding author: Katharina Merry Apriliani Angkawidjaja, dr, Dep/SMF Kedokteran Jiwa FK UNAIR/RSUD Dr.Soetomo Surabaya HP: 08123135195 | email: merry_prilice@yahoo.com 


\section{PENDAHULUAN}

Depresi adalah masalah kesehatan mental yang penting di masyarakat maju. Tujuan penulisan ini adalah karena depresi masih samar-samar ditemukan dan diperlakukan tidak memadai. Oleh karena ketidaktahuan dan prasangka, sekitar $50 \%$ orang yang depresi tidak mencari bantuan medis, sehingga mereka datang dengan keluhan fisik yang sebenarnya merupakan efek dari gangguan psikiatris [1].

Gangguan tidur merupakan gambaran yang paling menonjol pada gangguan depresi. Sebanyak 50-90\% pasien dengan depresi mengeluhkan gangguan tidur [2]. Yayasan Tidur Nasional 2003 melakukan survei orang dewasa berusia 65 tahun ke atas, mereka dengan kondisi penyakit medis dilaporkan secara signifikan mengalami lebih banyak keluhan tidur. Seiring banyaknya kondisi medis seseorang, kemungkinan mengalami kesulitan tidur juga meningkat. Depresi berat teridentifikasi pada $80 \%$ korban bunuh diri yang berusia lebih dari 74 tahun. Banyak korban bunuh diri lansia adalah janda dan lebih sedikit lajang, berpisah, atau bercerai, dibandingkan dengan orang dewasa yang lebih muda. Gejala depresif, status medis, status kesehatan yang dirasakan, kesulitan kognitif, beban yang dirasakan dan keputusasaan diidentifikasi sebagai risiko faktor-faktor untuk ide bunuh diri dan kematian pada orang dewasa yang lebih tua [3].

Perubahan neurofisiologi yang banyak diteliti pada depresi ialah gangguan tidur. Penderita dengan depresi umumnya mengeluhkan bangunnya terlalu pagi dan sulit tidur lagi, bersamaan pula dengan sering terbangun di malam hari [2].

Insomnia, salah satunya gejala depresi paling umum pada usia berapa pun dan terutama pada akhir hidup, merupakan faktor risiko independen untuk ide bunuh diri pada orang dewasa dan kematian bunuh diri pada orang tua. Pengobatan depresi yang agresif dapat mencegah bunuh diri, karena ide bunuh diri sangat erat kaitannya dengan gejala depresi pada individu orang tua. Memburuknya depresi dan keinginan untuk bunuh diri mengindikasikan kebutuhan untuk rawat inap psikiatris dan atau ECT [3].

\section{GANGGUAN TIDUR}

Diagnostic and Statistical Manual of Mental Disorder-5 (DSM-5) mendefinisikan insomnia sebagai gangguan dengan "keluhan utama tidak puas dengan kuantitas atau kualitas tidur," setidaknya terkait salah satu dari: kesulitan memulai tidur, mempertahankan tidur, dan bangun terlalu pagi; gejalanya harus menyebabkan tekanan yang signif- ikan atau penurunan fungsi dan harus terjadi setidaknya 3 malam per minggu untuk pada minimal 3 bulan; serta semua etiologi yang memungkinkan (misalnya, Gangguan tidur primer, komorbiditas kondisi medis atau kejiwaan) harus dipertimbangkan sebelum membuat diagnosis ini [3].

Pada orang dewasa yang lebih tua, secara subyektif dan obyektif, masalah tidur terkait dengan peningkatan risiko jatuh, akibat gangguan keseimbangan ambulasi, dan kesulitan visual. Kesulitan tidur kronis pada usia berapa pun dapat menyebabkan defisit perhatian, respons, memori jangka pendek, dan tingkat kinerja. Kontributor gangguan tidur pada orang dewasa yang lebih tua dapat mencakup komorbiditas penyakit medis atau kejiwaan, obat-obatan, gangguan ritme sirkadian, atau gangguan tidur-bangun tertentu [2-3].

Pada manusia, siklus tidur-bangun dikendalikan oleh jam endogen yang beroperasi selama periode 24 jam, disebut ritme sirkadian. Ritme ini disinkronkan dengan isyarat waktu eksternal ("zeitgebers") seperti siklus teranggelap, yang berfungsi sebagai isyarat waktu eksternal utama manusia. Alat pacu jantung sirkadian, terletak di nukleus suprachiasmatic, diketahui merosot seiring bertambahnya usia, yang mungkin menghasilkan ritme yang lebih lemah, lebih teratur. Sekresi malam hari dari melatonin endogen dan melemahnya isyarat lingkungan diketahui memainkan peran penting dalam siklus tidur-bangun. Adapun rangkaian sirkuit lain di hipotalamus yang mengatur tidur dan bangun secara tidak teratur, seperti sakelar "ON" dikenal sebagai wake promoter dan dilokalisasi dalam $t u$ beromammillary nucleus (TMN) dari hipotalamus; serta sakelar "OFF" dikenal sebagai promotor tidur dan terlokalisasi dalam ventrolateral preoptik nukleus (VLPO) hipotalamus. Dua neurotransmiter utama mengatur sakelar tidur / bangun: histamin dari TMN dan GABA (Gamma AminoButyric Acid) dari VLPO. Dua set neuron lain terlibat sebagai pengatur saklar tidur / bangun: neuron yang mengandung neuron lateral hipotalamus (LAT) dan neuron yang peka terhadap melatonin dari suprachiasmatic nukleus (SCN). Hipotalamus lateral berfungsi untuk menstabilkan dan meningkatkan keterjagaan melalui neurotransmitter peptida yang dikenal dengan dua nama berbeda: orexin dan hypocretin. Sedangkan SCN adalah jam internal otak, atau alat pacu jantung, dan mengatur input sirkadian ke saklar tidur-bangun sebagai respons terhadap hormon seperti melatonin, dan oleh siklus terang / gelap [2,4-6].

Siklus tidur terdiri dari 3 fase, yaitu: fase bangun, fase Non-Rapid Eye Movement (NREM) dan fase REM Fase NREM terbagi menjadi 4 tahap. Tahap 1 tidur NREM 
disebut "drowsy period", awal tidur yang bila terbangun kembali, individu sering merasa seperti tidak tidur. Tahap 2 mulai menunjukkan adanya sleep spindle, merupakan periode aktivitas dari interaksi thalamus-cortex. Tahap 3 dan 4, disebut slow wave sleep (SWS), merupakan tahapan tidur dalam yang ditandai gelombang Delta. Fase REM termasuk tidur ringan dan disebut juga paradoxical sleep. Sedangkan untuk EEG fase REM tidak berbeda dengan fase bangun. Periode tidur dalam semalam terdiri dari 5 episode aktivitas NREM-REM. Episode REM pertama muncul sekitar 90 menit setelah tidur, yang disebut REM latency dan berkurang pada individu dengan depresi, narkolepsi, dan sleep apnea [7-8].

Adapun beberapa penyebab gangguan tidur pada lansia meliputi: penyakit Fisik/Medis \{radang sendi, PPOK (Penyakit Paru Obstruktif Kronis), CHF (Congestive Heart Failure), BPH (Benign Prostat Hyperplasia), gangguan neurologis\}; gangguan kejiwaan/ psikiatri (65\% depresi berat, $61 \%$ gangguan panik, dan $44 \%$ gangguan kecemasan); obat-obatan ( $\beta$-blocker, bronkodilator, kortikosteroid, dekongestan, dan diuretik, juga obat-obatan kardiovaskular, neurologis, psikiatrik, dan gastrointestinal lainnya); serta aktivitas imun (sitokin seperti IL-2, Interferon $\alpha 2$, dan factor nekrosis tumor, Natural Killer (NK) pada depresi), selanjutnya berimplikasi pada beratnya insomnia [9].

\section{DEPRESI LANSIA}

Depresi adalah suatu sindrom yang ditandai sejumlah gejala klinik yang manifestasinya bisa berbeda pada masing-masing individu [2]. Depresi Lansia adalah bukan sekedar perasaan sedih. Depresi mengenai seluruh diri individu termasuk perasaan, pikiran dan kesehatan fisik. Depresi Lansia sulit diketahui, dapat tampak sebagai bagian gejala penyakit medis lain. Umumnya keluarga dan caregiver melihat gejala depresi sebagai bagian normal dari proses penuaan dan sebagai akibat kehilangan dalam kehidupan yang dialami oleh semua manusia [10].

Prevalensi depresi berat di antara orang berusia 65 tahun/ lebih diperkirakan $1,5 \%$ pada wanita dan $0,2 \%$ pada pria, dengan sekitar seperempat dari prevalensi keseluruhan terjadi pada dewasa muda. Prevalensi depresi di kemudian hari tercatat setinggi 11,19\% dengan tingkat yang sama untuk pria $(10,19 \%)$ dan wanita $(11,44 \%)$ [3$11]$.

Beberapa penyebab Depresi Lansia terkait faktor neurobiologi meliputi: Atropi struktur otak, penurunan kadar serotonin yang mempengaruhi dopamine, dan peran Sitokin penuaan (IL-6; IF- $\alpha$ ) yang disebut juga inflammag- ing. Serta faktor resiko seperti : gangguan fisik, gangguan neurologis, gangguan fungsi kognitif, gangguan metabolik (Diabetes Mellitus, Hipertensi), gangguan hormonal (menopause), dan kesepian [3,12-13].

Beberapa penyakit juga berkomorbid dengan Depresi Lansia meliputi : Penyakit kronis (stroke, PJK, Parkinson, Alzheimer, multiple sclerosis, SLE (Systemic Lupus Erythomatous), COPD (Chronic Obstructive Pulmonary Disease), penyakit ginjal, penyakit hati seperti Hepatitis $\mathrm{C}$, dan Diabetes); Nyeri (nyeri kronis, fraktur, Osteo Arthritis, Rheumatoid Arthritis, vasculitis); dan gangguan hormon (tiroid, hormon seks, menopause, hormon menyusui seperti oksitosin dan prolactin) [9,14-16].

Pada Lansia, gejala depresi meliputi tidak hanya gejala utama yaitu: afek depresif, anhedonia, dan anergi; ditambah juga gejala tambahan: konsentrasi dan perhatiannya berkurang, harga diri dan kepercayaan diri berkurang, gagasan tentang rasa bersalah dan tidak berguna, pandangan masa depan yang suram dan pesimistis, gagasan atau perbuatan membahayakan diri atau bunuh diri, tidur terganggu, nafsu makan berkurang. Namun juga keluhan lain yang lebih sering muncul seperti: keluhan somatik (pusing sulit tidur, rasa nyeri, pandangan kabur, konstipasi, perubahan berat badan), gangguan psikomotor (agitasi/ hiperaktivitas, acuh, libido menurun, variasi diurnal suasana hati), psikologis (disforik, kognisi negatif, irritabel, menarik diri). Sehingga pada Depresi Lansia gejala yang kerap muncul berupa sindroma penurunan (depletion syndrome) seperti penarikan diri, apatis, kekurangan energi atau kurang aktif [3,10,17-18].

\section{GANGGUAN TIDUR PADA DEPRESI LANSIA}

Penuaan dikaitkan dengan penurunan kualitas tidur, dan tersebar luas di antara orang dewasa lanjut usia. Sebanyak $40 \%$ orang lanjut usia melaporkan masalah tidur, dan sebanyak 50-90\% pasien dengan depresi mengeluhkan adanya gangguan tidur. Keluhan tidur yang sering dikemukakan adalah sulitnya masuk tidur, seringnya terbangun di malam hari, dan terbangun dini hari. Kualitas tidur yang buruk pada lanjut usia dikaitkan dengan peningkatan risiko gangguan kognitif dan demensia [2-3,19-20].

Perubahan irama sirkardian terjadi pada banyak orang lanjut usia, terutama pada pasien Demensia Alzheimer. Perubahan yang terjadi dapat berupa penurunan rapid-eye movement, dan slow-wave sleep, yang menyebabkan terjaga sepanjang hari dan tidak bisa tidur di malam hari [21]. 
Penderita depresi yang mengalami gangguan tidur memperlihatkan gangguan ritmik sirkardian, sekresi kortisol meningkat malam hari, konsentrasi melatonin darah menurun, kadar serotonin, noradrenergic, dopamine dan asetilkolin rendah. Proyeksi neuron tersebut ke berbagai area di otak ini mendasari keterlibatannya pada gangguan psikiatrik [2,22].

Serotonin berfungsi sebagai pengatur tidur, selera makan, dan libido. Neuron serotoninergik berproyeksi dari nucleus rafe dorsalis batang otak ke korteks serebri, hypothalamus, thalamus, basalis ganglia, septum dan hippocampus. Sistem serotonin yang berproyeksi ke SCN hipotalamus berfungsi mengatur ritmik sirkadian, seperti siklus tidur bangun, suhu tubuh, dan fungsi HypothalamicPituitary-Adrenal (HPA) Axis. Ritmik sirkardian dikacaukan oleh peningkatan keterjagaan nocturnal, disamping peningkatan Corticotropin Releasing Hormon $(\mathrm{CRH})$, somatostatin, hiperkortisol, dan penurunan serotonin terlibat dalam proses ini [2].

Badan sel neuron noradrenergic terletak di Locus Cereolus $(L C)$ batang otak dan berproyeksi ke korteks serebri, sistem limbic, basal ganglia, hipotalamus, dan thalamus. Ia berperan dalam memulai dan mempertahankan keterjagaan (proyeksi ke limbic dan korteks). Stressor akut dapat meningkatkan aktivasi LC. Selama terjadi aktivasi fungsi LC, fungsi vegetative seperti makan maupun tidur menurun. Sedangkan stressor menetap dapat menurunkan kadar norepinefrin di forebrain medial. Penurunan ini dapat menyebabkan anergia, anhedonia, dan penurunan libido pada depresi. Sedangkan, sistem mesokorteks-mesolimbik jaras dopaminergik berproyeksi ke region korteks orbitofrontal dan prefrontal. Penurunannya pada sistem ini terkait gangguan kognitif, motorik, dan hedonia sebagai gejala depresi. Untuk Neuron kolinergik yang mengandung asetilkolin, terdistribusi difus di kortex serebri dan mempunyai hubungan timbal balik dengan sistem monoamine. Abnormalitas kadar kolin yang merupakan precursor asetilkolin terdapat di otak pasien depresi. Sedangkan GABA memiliki efek inhibisi terhadap monoamine, terutama pada sistem mesokorteks dan mesolimbic, dimana penurunan GABA tampak pada pasien depresi. Stressor kronik pun dapat mengurangi kadar GABA [2].

Gangguan tidur merupakan gambaran yang paling menonjol pada gangguan depresi. Sebanyak 50-90\% pasien dengan depresi mengeluhkan gangguan tidur. Insomnia ini tidak hanya dikeluhkan secara subyektif, tetapi juga secara obyektif, yaitu dengan menggunakan EEG tidur. Abnormalitas tidur REM membaik dengan membaiknya depresi.
Penelitian lain menyebutkan abnormalitas tidur REM dan SWS menetap meskipun telah terjadi remisi atau tidak lagi menggunakan obat. Menetap atau adanya residu gangguan tidur dikaitkan dengan tingginya risiko kekambuhan. Menetapnya pengurangan SWS dikaitkan cepatnya atau seringnya terjadi rekuren depresi [2].

Penelitian telah menemukan terapi perilaku itu mungkin, dalam banyak kasus, lebih efektif daripada obat untuk insomnia. Di orang dewasa yang lebih tua yang berisiko lebih besar untuk mengalami efek samping serius yang berkaitan dengan farmakoterapi untuk insomnia dan yang sering berisiko lebih besar untuk mengalami polifarmasi, pendekatan nonfarmakologis harus menjadi yang pertama pilihan pengobatan dipertimbangkan [3].

Untuk penatalaksanaan secara umum adalah kombinasi dengan intervensi farmakologis dan nonfarmakologis. Intervensi farmakologis dapat diberikan mulai antidepressant (golongan Selective Serotonin Reuptake Inhibitor/ SSRI, modulator reseptor benzodiazepin, agonis reseptor melatonin, dan inhibitor reseptor orexin). Agomelatin, antidepresan baru, yang bekerja sebagai agonis melatonergik dan antagonis pada reseptor 5HT2C dapat menyinkronkan kembali gangguan ritmik sirkardian sehingga bermanfaat pada depresi [3].

Untuk Depresi Lansia, Antidepresan golongan SSRI dapat ditoleransi dengan baik, namun jangan diberhentikan langsung, harus di-tappering down, karena dapat terjadi mual dan diare serta efek samping seksual. Pada dosis tinggi terjadi hiponatremia (SIADH/ Syndrome of Inappropriate Antidiuretic Hormone Secretion). Fluoxetin bukan obat pilihan untuk lansia karena waktu paruh yang panjang hingga 4-6 hari, metabolitnya 9,3 hari serta potensi interaksi obat, juga menginduksi ansietas, gangguan tidur dan agitasi, serta efek samping antikolinergiknya. Meskipun benzodiazepin umumnya diresepkan untuk insomnia di orang dewasa yang lebih tua, ada risiko signifikan yang terkait dengan kelas obat ini, terutama pada orang dewasa yang lebih tua, termasuk yaitu peningkatan risiko jatuh, gangguan kognitif, dan kecelakaan berkendara [2-3,10,1819].

Pengobatan Non-Farmakologis meliputi penerapan perilaku yang efektif (seperti CBT, BBTI, Sleep Hygiene Program dan Manipulasi lingkungan/ sosial [3,19,23].

Untuk masalah gangguan tidur, menurut rekomendasi The Consensus Statement (NIH, 1990) dicanangkan Sleep Hygiene Programs : [3,24]

1. Pembiasaan waktu tidur dan bangun

2. Menggunakan kamar tidur khusus untuk tidur 
3. Jam makan yang teratur

4. Menurunkan intake cairan di malam hari

5. Menghindari alkohol,kafein, dan nikotin

6. Melakukan ritual sebelum tidur

7. Meminimalkan cahaya dan kebisingan di waktu tidur dan sepanjang malam.

8. Termasuk menghindari beberapa jenis obat seperti diuretik, antidepresan (SSRI, SNRI) yang agar tidak dikonsumsi malam hari.

Cognitive-Behavioral Therapy (CBT) untuk insomnia telah terbukti memiliki kemanjuran jangka pendek dan jangka panjang pada orang dewasa yang lebih muda dan lebih tua. Pendekatan ini menggabungkan kontrol stimulus dan atau pembatasan tidur dengan restrukturisasi kognitif, kebersihan tidur yang baik (satu set pedoman untuk kebisaaan tidur-bangun yang sehat), dan relaksasi. Program dari CBT biasanya terdiri dari 6-10 sesi mingguan yang dikelola oleh khusus dokter terlatih [3,24-26].

Brief Behavoural Therapy for Insomnia (BBTI) memiliki fokus perilaku eksklusif; komponen inti adalah kontrol stimulus dan pembatasan tidur. Beberapa uji acak dilakukan dan menunjukkan BBTI efektif pada orang dewasa yang lebih tua [3].

Cognitive Behavioral Therapy for Insomnia (CBTI) berasal dari prinsip terapi Cognitive Behavioural Therapy for Depression (CBT-D) yang sudah mapan. CBT-D adalah pengobatan yang efektif untuk dewasa lebih tua untuk mengurangi keparahan depresi. Meskipun demikian, CBT-D tidak termasuk intervensi CBT-I yang hanya mengatasi komorbiditas insomnia. Aktivasi perilaku, atau penjadwalan aktivitas, adalah intervensi pertama yang dimasukkan dalam program CBT-D. Aktivasi perilaku dapat disinkronkan dengan strategi CBT-I seperti kontrol stimulus, pembatasan tidur dan kebersihan tidur untuk meningkatkan efek terapeutik [24].

Pembingkaian atau restrukturisasi kognitif adalah intervensi inti dalam program CBT-I dan CBT-D. Program standar CBT-I secara khusus menargetkan keyakinan disfungsional tentang tidur, daripada menangani kognisi aneh dan suasana hati yang tertekan. Dalam CBT hibrida untuk program insomnia dan depresi/ Cognitive Behavioural Therapy for Insomnia and Depression (CBT-I-D), restrukturisasi kognitif dapat diperluas untuk mengatasi kedua keyakinan disfungsional tentang tidur dan pikiran otomatis negatif yang memicu depresi komorbiditas. Namun bukti terbaru yang menjanjikan menunjukkan bahwa CBT-I memiliki dampak positif pada insomnia dan keparahan depresi [24].

\section{RINGKASAN}

Depresi adalah masalah kesehatan mental yang sering memberikan gejala samar dan diperlakukan tidak memadai, sehingga karena ketidaktahuan, sekitar 50\% orang depresi tidak mencari bantuan medis. Sebanyak 20\% lansia yang tinggal sendirian di rumah memiliki gejala depresi, dan hanya ada $3-4 \%$ dari mereka yang memenuhi kriteria untuk depresi. Tujuan penulisan ini adalah karena Depresi Lansia secara klinis bukan bagian dari penuaan normal tetapi harus dianggap sebagai penyakit medis yang dapat diobati, meskipun tetap dikaitkan dengan masalah penuaan, seperti kehilangan, kesedihan, dan penyakit fisik.

Gangguan tidur merupakan gambaran paling menonjol pada gangguan depresi. Sebanyak 50-90\% pasien depresi mengeluhkan gangguan tidur. DSM-5 mendefinisikan insomnia sebagai gangguan tidak puas dengan kuantitas/ kualitas tidur, dan salah satu dari: sulit memulai tidur, mempertahankan tidur, dan bangun terlalu pagi, yang menyebabkan tekanan/ penurunan fungsi setidaknya 3 malam per minggu, minimal 3 bulan.

Pada lansia, gangguan tidur terjadi akibat kelemahan ritme alat pacu jantung sirkadian, berkurangnya sekresi melatonin endogen, dan melemahnya isyarat lingkungan untuk sikronisasi sirkardian. Depresi Lansia juga berkomorbid dengan gangguan tidur melalui berbagai neurotransmitter. Beberapa penyakit medis seringkali berkomorbid dengan Depresi Lansia, yaitu: Penyakit vaskular, jantung, neurologis, ginjal, hati, diabetes, nyeri, dan gangguan hormone.

Terapi farmakologis dapat diberikan antidepresan (golongan SSRI) dan antiinsomnia (zalepion, zolpidem). Agomelatin, merupakan terapi terbaru antidepresan sekaligus agonis melatonergik untuk menyinkronkan kembali gangguan ritmik sirkardian (gangguan tidur) pada depresi. Sedangkan terapi norfarmakologis juga penting diperlukan yang meliputi Sleep Hygiene Program, BBTI, CBT (CBT-I, CBT-D, CBT-I-D).

\section{DAFTAR PUSTAKA}

[1] Alibasic E, Ramic E, Bajraktarevic A, Karic E, BaticMujanovic O, Ramic I, et al. Geriatric Depression in Family Medicine. Mater Socio Medica. 2018;30(1):26.

[2] Amir N. Depresi Aspek Neurobiologi Diagnosis dan Tatalaksana. edisi kedu. Jakarta: Badan Penerbit Fakultas Kedokteran Universitas Indonesia; 2016. 2934, 144-147 p.

[3] Sadock BJ et al. Kaplan \& Sadock's Comprehensive 
Textbook of Psychiatry. tenth edit. New York: Wolters Kluwer; 2017.

[4] Reiter RJ, Mayo JC, Tan DX, Sainz RM, AlatorreJimenez M, Qin L. Melatonin as an antioxidant: under promises but over delivers. J Pineal Res. 2016;25378.

[5] Xie Z, Chen F, Li WA, Geng X, Li C, Meng X, et al. A review of sleep disorders and melatonin. Neurol Res [Internet]. 2017;39(6):559-65. Available from: http://dx.doi.org/10.1080/01616412.2017.1315864

[6] Stahl SM, Dunitz M. Psychopharmacology of Antipsychotics. UK: Cambridge Univercity Press; 2013.

[7] Higgins, Edmund S. MSG. The Neuroscience of Clinical Psychiatry: The Pathophysiology of Behaviour and Mental Illness. USA: Lippincott Williams \& Wilkins; 2007. 141-152 p.

[8] Sadavoy J, Jarvik LF, Grossberg GT, Meyers BS. Comprehensive Textbook of Geriatric Psychiatry. third edit. New York: W. W. Norton \& Company Inc.; 2004. 792-794 p.

[9] Coffey, C. Edward GDP. Textbook of Geriatric Neuropsychiatry. second edi. Washington DC: The American Psychiatric Press; 2000. 402-407 p.

[10] Maramis MM. Depresi Pada Lanjut Usia. J Widya Med Surabaya. 2014;Vol.2 No.1(April):39-50.

[11] Price EC, Gregg JJ, Smith MD, Fiske A. Masculine Traits and Depressive Symptoms in Older and Younger Men and Women. 2015;(152).

[12] Chigogora S, Zaninotto P, Kivimaki M, Steptoe A, Batty GD. Insulin-like growth factor 1 and risk of depression in older people: the English Longitudinal Study of Ageing. Nat Publ Gr. 2016;6(July):1-7.

[13] Jae S, Shin A, Kang D. Hormone-related factors and post-menopausal onset depression: Results from KNHANES ( 2010 - 2012 ). J Affect Disord. 2015;175:176-83.

[14] Sin ELL, Chen YL, Ling H, Shwu L, Lee H, Mao C, et al. The relationships between brain structural changes and perceived loneliness in older adults suffering from late - life depression. 2018; (November 2017):606-12.

[15] Rutherford BR, Taylor WD, Brown PJ, Sneed JR, Steven P. Biological Aging and the Future of Geriatric Psychiatry. 2016;00(00):1-10.

[16] Casey DA. Depression in Older Adults: A Treatable Medical Condition Depression Antidepressants Electroconvulsive therapy. Prim Care Clin Off Pract. 2017;1-12.

[17] Maslim R. PPDGJ-III, Pedoman Penggolongan dan Diagnosis Gangguan Jiwa edisi III. Jakarta; 2010.
[18] Chew-Graham C, Baldwin R, Burns A. Integrated Management of Depression in the Elderly. New York: Cambridge University Press; 2008. 1-10 p.

[19] Dinapoli EA, Gebara MA, Kho T, Butters MA, Gildengers AG, Albert SM, et al. Subjective-Objective Sleep Discrepancy in Older Adults With MCI and Subsyndromal Depression. 2017;

[20] Yu J, Mahendran R, Nur F, Abdullah M, Kua E, Feng L. Self-reported sleep problems among the elderly: A latent class analysis. Psychiatry Res. 2017;(June):1-6.

[21] Brodaty H, Sanford F. Behavioral and Psychological Symptoms of Dementia. USA: IPA Educational Pack; 2003.

[22] Michaels MS, Joiner TE. Insomnia and mental disorders Total sleep time as a predictor of suicidal behaviour. 2017;732-8.

[23] Raue PJ, Mcgovern AR, Kiosses DN, Sirey JA. Advances in Psychotherapy for Depressed Older Adults. 2017;

[24] Sadler P, Mclaren S, Klein B, Jenkins M. Advancing cognitive behaviour therapy for older adults with comorbid insomnia and depression. Cogn Behav Ther. 2017;6073(August):1-16.

[25] Wenzel A, Dobson KS, Hays PA. Cognitive Behavioral Therapy Techniques and Strategies. first edit. Washington: American Psychological Association; 2016. 21-57 p.

[26] Sadock BJ. Kaplan and Sadock's Synopsis of psychiatry. 11th editi. New York: Wolters Kluwer; 2015. 